\title{
Management Issues of SMEs in Turkey from the Perspective of Sustainability
}

\author{
Nida Türegün ${ }^{1, *} \&$ Orçun Türegün ${ }^{2}$ \\ ${ }^{1}$ School of Applied Sciences, Özyeğin University, Istanbul, Turkey \\ ${ }^{2}$ Faculty of Economics and Administrative Sciences, Yeditepe University, Istanbul, Turkey \\ *Correspondence: School of Applied Sciences, Özyeğin University, Nişantepe Mah. Orman Sok. 34794 Çekmeköy, \\ Istanbul, Turkey. Tel: 90-216-564-9826. E-mail: nida.turegun@ozyegin.edu.tr
}

Received: June 23, 2017 Accepted: July 14, $2017 \quad$ Online Published: July 25, 2017

doi:10.5430/mos.v4n3p25 URL: https://doi.org/10.5430/mos.v4n3p25

\begin{abstract}
Sustainability for SMEs is a process of development target to be achieved by increasing the competitiveness in the global market. In this context, the purpose of this study is to investigate the SMEs in Turkey within the framework of management issues and corporate governance viewpoint and to present an outline of possible solutions. Another purpose of this study is to contribute management literature in terms of shedding lights on the relations of sustainability and management practices on SMEs to raise awareness. In order to conduct this study method of detailed literature review is used. Detected management issues and solutions are examined into four main categories, which are (a) the lack of awareness of the sustainability and failure of implementation of this concept to the management practices, (b) lack of understanding of the relationship between the expectations of stakeholders on sustainability and company's future interests, (c) lack of the vision about sustainability and presence of unclearly defined rules, roles and processes within the companies, (d) lack of skills to analyze the short and long term effects to the company of not taking sustainability concept into decision making mechanisms.
\end{abstract}

Keywords: sustainability; SMEs; management issues

\section{Introduction}

SMEs are the backbone of Turkish economy, which constitute $99.8 \%$ of overall business and provide $74.2 \%$ of total employment. For this reason, SMEs appear to be the key players and vitally important for Turkey to achieve balanced economic, social and environmental development. In this manner, their prosperity and successful performance are basically essential to the contribution of the development of the Turkish economy, and thus, the priority must be given to the elucidation of the management issues and trying to solve them. Hence, SMEs should consider the concept of sustainability in their strategic plans, so that they can fulfill the needs of future generations and enable alliances on strategic and global basis. The strategic planning can be done by good corporate governance models, educated, skillful and aware managers and staffs. Although, Turkish law does not obligate corporate governance practices to SMEs, it should also be understood that the adaptation of corporate governance practices would contribute to the SMEs' performances in the micro-scale and nation's economy in the macro-scale.

The purpose of this study is to investigate the SMEs in Turkey within the framework of management issues and to present an outline of possible solutions. Another purpose of this study is to contribute management literature in terms of shedding lights on sustainability and managerial applications on SMEs to raise awareness in academia and professionals.

In order to conduct this study method of detailed literature review is used. Detected management issues and solutions are examined into four main categories, which are (a) the lack of sustainability awareness and lack of adaptation of this concept to the management applications, (b) lack of understanding of the relationship between the expectations of stakeholders on sustainability and company's future interests, (c) lack of the vision on sustainability and unclearly defined rules, roles and processes within the companies, (d) lack of inability to analyze the short and long term effects to the company by not taking sustainability concept into decision making mechanisms. 


\section{The Place of SMEs in the Turkish Economy}

SMEs are small economic units, which have a quite flexible structure to adapt innovation for the market. That's why they are the backbone of the global economy. In reaction to increased global competition, SMEs have developed rapidly and become the most important element of the market (ACCA, 2010). Thus, SMEs undertakes serious roles in nations' economic growth and development. SMEs have taken their place in the economic literature as the manifestation of entrepreneurship, the formation of social stability, the majority provider of employment and the great potential of export.

Especially in recent years, SMEs have become the most dynamic element of a healthy economy by increasing rapidly in developed and developing countries. The main factors in the need for SMEs are listed as technical changes, growth in the service sector and meeting the requirements of growing demand, increase in the third-world competition, increase in the energy prices and the slowdown of world demand, and rising in the entrepreneurial culture (Aksümer, 2015).

Although, SMEs constitute the fundamental dynamics of the whole economy, there is no consensus on the SME definition in the literature (Demirci, 2010). As a matter of fact, it is impossible to make a clear definition for these enterprises by their nature. The definition of SMEs differs according to countries and even between different regions of the same country because of the various levels of industrialization, business lines and production techniques (Karataş, 1991).

The clear definition of SMEs in Turkey is stated by the "Regulation on Definition, Qualifications and Classification of Small and Medium Sized Enterprises" in 2012 (TOBB, 2012). The definition has been divided into three categories as micro, small and medium sized SMEs. According to definition, micro sized SMEs are enterprises that have annual sales revenue or financial balance sheet totals up to 1 million TL, and employ up to 10 people. Small sized SMEs are enterprises that have annual sales revenue or financial balance sheet totals up to 8 million TL and employ up to 50 people. Medium sized SMEs are enterprises that have annual sales revenue or financial balance sheet totals up to 40 million TL and employ up to 250 people.

Turkey is a developing country, which has a strong competitive business environment that is brought by the globalization, and SMEs play a noteworthy and vital part in the development of Turkish economy and competitiveness. Globalization expands the innovative progress and it speeds up the innovation, so that the life spans of the products are getting shorter. This innovative improvement has driven customers to change their preferences very often. In this way, SMEs play an important role in this dynamic business environment. They can simply adjust themselves to the changing market conditions in the quickest way possible. As per the structure, SMEs are one of the most significant factor for the social development in the best interest of Turkey as they give support to employment and local balanced development with their flexible production features (Ergün, 2012).

SMEs in Turkey generate $99.8 \%$ of all organizations. They provide $74.2 \%$ of the overall employment with $54.7 \%$ of all wages and salaries. The employment rate is higher in trade sector with $28.3 \%$. SMEs creates $63.8 \%$ of the turnover and $53.3 \%$ of gross investment (tangible goods). They represent $39.9 \%$ in wholesale and retail trade, $15.7 \%$ in transportation and 12.6\% in manufacturing industries (TÜIK, 2015). Furthermore, SMEs generate $91.6 \%$ of the total imports and $56.4 \%$ of the total exports in Turkey. (TÜIK, 2014). These rates demonstrate that SMEs are the essential financial units in the Turkish monetary framework.

\section{Importance of an Effective Management on Sustainability for SMEs}

Today, enterprises face with more conscious society due to globalization. The expectations of society which is placed on enterprises have grown in recognition of environmental, social, ethical and human rights issues. In order to survive in the intense competitive environment, enterprises will be better off if they integrate those expectations into their company policies and governance models. Moreover, managers are also expected to include these issues into their decision-making processes. (SAM, 2010)

The society's approach of selecting an enterprise to interact with, has shifted in the direction of choosing an enterprise, which incorporates information about social and environmental issues. The biggest problem among SMEs in disclosing that information is the lack of the knowledge of sustainable practices and embedding it in their strategy development (Collins et al., 2011).

Sustainability is the ability to continue by protecting the balance of the eco-system (controlling natural resources, abating pollution levels etc.), encouraging moral practices, helping societies by opening up opportunities for social 
(generating employment, contributing local community etc.) and economic (fair distribution of salaries, complying with payment commitments etc.) development (Kocmanová et al., 2011) Hence, sustainability is a tool for the sustainable development. Sustainable development is the progress, which satisfies the needs of present generation by giving respect to future generations' needs and not harming those (Günerergin et al., 2012). Consequently, the responsibility of the enterprise does not only cover the responsibilities to the owners by maximizing profits, moreover it should practice activities morally concerning the eco-systems in which it operates, and the managers should also be liable for the proper management of the enterprise's resources (SAM, 2010). Thus, enterprises that practice sustainability are expected to function more compatible with the related community, remain in the market and increase profitability.

Growing concerns about the possible future climate changes have revealed the fact that environment and economy can no longer be taken into consideration as two unrelated entities. It is expected that there will be a $70 \%$ increase in the greenhouse gas emissions by 2050 and $4-5{ }^{\circ} \mathrm{C}$ increase in the average temperature levels by 2100 . Moreover, the demand for food production will be increased by $70 \%$ by 2050 , which will put pressure on natural resources. So there is a need for global shift of the collective mindset to a more resource-efficient economy (OECD, 2010).

The procedures and strategies for sustainability cannot be completely understood, exclusive of SMEs' practices. In Turkey, SMEs provide $74.2 \%$ of the total employment by generating $99.8 \%$ of all businesses. When we take into consideration these statistics, it is clear that SMEs play a crucial role in the implementation of sustainability (TÜIK, 2015). Thus, the basis of economy and morals turns out to be concept of sustainability in the 21 st century. Besides it is one of the most significant means of opportunities and risks for enterprises, so that decision makers should understand the connection between environment, society and enterprises (Collins et al., 2011).

Different ideas have been debated on sustainability concept to generate a more ethical, effective, practical and transparent way of doing business among academic and business environments. Keeping in mind that the end goal is to accomplish sustainability, SMEs ought to decide about their procedures and strategies, which will help them to provide different windows of opportunities to benefit and to maintain their strategic distance from the threats for future achievement (Günerergin et al., 2012)

The center of an enterprise strategy includes economic, social and environmental issues together with management practices. They are the vital part of everyday operations, which invigorate work for achievement and function as a pointer of threat and risk, and push for capturing opportunity. Though there is no direct connection among corporate governance and environmental functioning, it is expressed that both of the functioning separately contribute to the general functioning (Kocmanová et al., 2011). The indicators of environment ought to describe the degree of effect of an enterprise on nature (water, soil surrounding, air etc.) with respect to sustainable development. They concentrate on using inputs (materials, energies, water etc.) and the texture of outputs (material wastes, emissions, waste water etc.).

By embracing the idea of sustainability and applying it fully through the entire organization, the enterprise can create procedures, strategies and management models that generate value to society, economy and environment together with making higher profits in the short and long run. In this regard, the concepts of sustainability and management practices are connected and offer a new governance approach. It is fundamental to build up a system with people, procedures and processes to maximize the value of an enterprise, which consolidates a positive feedback to enterprise's risk and opportunities and have possible impact on the performance of the organization (SAM, 2010).

\section{Detected Management Issues of SMEs on Sustainability and Solutions}

Sustainability turns out to be ethical and financial basic for SMEs and it is a standout among the most significant sources of opportunities and risks for enterprises. Hence, the connection between environment, society and enterprises should be understood by the managers of SMEs (Collins et al., 2011).

The cumulative effects of SMEs on the environment are heavy, since they are short-term oriented enterprises, which desire to earn higher profits at short notice, and do not raise instant anxiety for outcomes in the long run. Nevertheless, there needs to be a drastic shift toward sustainability in the way enterprises and managers behave and shape their actions (Johnson, 2012). The main reasons for the failure of this shift are shown under four main headings. 
4.1 The Lack of Awareness of the Sustainability and Failure of Implementation of This Concept to the Management Practices

According to European Commission (2004), SMEs generates approximately $70 \%$ of global pollution. The problem in this regard is that most of the SMEs are unaware of their environmental effects. Since SMEs are unaware of environmental impacts and want to maximize their short-term profits, they use low quality materials to substitute high quality materials to cut down their costs, which can slowly destroy the environment.

Another problem in this regard is that owner-manager's unwillingness to implement sustainability practices (Johnson, 2012). Environmental issues like harmful wastes, global warming, toxic pollution are all arise from wrong decision-making by managers where they chase money and ignoring ethical and sustainability decisions. If an enterprise has a great deal of waste material, then it would be the manager's decision to take sustainable steps (Kee, 2013).

Environment is also getting harmed by the unethical and immoral behavior of the enterprises. Education is the key player in creating awareness on sustainability under moral and ethical aspects. The consciousness about the environment and ecology should be given by parents and schools in childhood stage, which would help the overall society for a sustainable world. Therefore, every person should be involved in environmental sustainability practices (Davis, 2010).

Although the overall awareness about the sustainability practices has been increased by informal environmental promotions, campaigns and standards over the last years, SMEs are still not fully aware of the relation between the costs and benefits and also advantages of adapting the eco-efficient practices into their business models (Dhanoo, 2011). They, moreover, are not fully aware of the regulations in their industry related to the environmental impacts. Besides they are ignorant of the needs of future generations. SMEs are not ready to invest in obtaining the pertinent knowledge from the market to adapt sustainability changes (OECD, 2010).

Although there are some governmental rules and procedures for ecological protection, it has been observed again and again that the individual small enterprises are unsuccessful to comply with these rules (Dhanoo, 2011). The common problems that are connected with mostly Turkish SMEs include an absence of learning in regards to environmental issues and not knowing the potential advantages of ecological management. Furthermore, they do not have the skills and the proper or adequate instruments, additionally, they have limited incentives for embracing sustainability awareness.

In order to increase the sustainability awareness in Turkey, following solutions for SMEs can be advised (Dhanoo, 2011; Johnson, 2012).

1. A large spectrum of management tools that are related to sustainability should be developed to help the managers as well as the staff in different divisions to incorporate sustainability viewpoints into traditional management practices.

2. A common sustainability approach for everyone ought to be avoided. Especially, SMEs should be capable to incorporate sustainability management tools that are related to their specific objectives and conditions, but there is something that should be kept in mind that all of the tools will not be applicable to all kinds of SMEs. The critical thing is all SMEs, individually, should pick the most suitable instruments for their specific management needs.

3. The local ecological ability should be built in order to conquer SMEs knowledge deficiency.

4. The support initiatives related to sustainability for SMEs should be promoted more. Even though Turkish SMEs are supported by (Small and Medium Enterprises Development Organization of Turkey, Technology Development Foundation of Turkey, Ministry of Food Agriculture and Livestock of Turkey etc.) authorities, it should be promoted more and raise the awareness of the benefits of obtaining sustainability practices.

5. Corporate social responsibility should be accepted among SMEs. The significance, opportunities and advantages should be explained in details.

6. There should be more governmental education and tuition about sustainability to help SMEs to build up their individual strategic methods to the notion.

Adopting these sustainability solutions to SMEs will contribute to reaching Turkey's 2023 goals. In order to succeed these goals there has to be green growth, sustainable and human-centered development among businesses and SMEs (MOD, 2012). 


\subsection{Lack of Understanding of the Relationship Between the Expectations of Stakeholders on Sustainability and Company's Future Interests}

Practicing sustainability among SMEs would be effective to enhance their business and help to get competitive edges. These edges can extend from better-quality employee procurement to enhanced relations with stakeholders (Johnson, 2012).

The concept of sustainability and its significance is being communicated to the public (via commercials, conferences, advertisements, news etc.) to raise awareness. Accordingly, people are started to search for enterprises that practice sustainability to interact with. This awareness will increase even more with each passing day and it would only harm the reputation of the enterprise, if it does not adopt sustainability practices. It is vital to implement those practices since it would bring more advantages than disadvantages to the related enterprise. Besides, the stakeholders are begun to understand and realize the importance of this situation with each passing day (Kee, 2013).

The expectations of the stakeholders are increasing in the environmental and social issues. They also ask for the involvement in the corporate social responsibility from the enterprises. Before the enterprises are pressured by the stakeholders to apply sustainability practices, SMEs should start to redefine the link between their enterprise and the environment. Moreover, they need to consider the stakeholders as a source of advantage for competitiveness and strategic management (Kuhndt et al., 2003).

The environmental preservation and the benefits of some stakeholders are disregarded in the traditional "shareholder primacy theory" (Freeman, 2010). However, this perspective is changing, especially within the large companies. The perspective, moreover, has to be changed among the SMEs as well and they must develop their own sustainability strategies before it is too late. In order to develop those strategies, they have to carry out an analysis for their local environment in the first place. Then they have to check over their market opportunities and evaluate their survival potential in the competitive market by adopting their sustainability strategies. In this manner, the optimum allocation can be accomplished, meaning that big advantages can be obtained with minimum resource consumption and allocation (Changxian et al., 2009). Thus, SMEs play a crucial role in the development of a nation's economy, only if they take their responsibilities over social and environmental issues. The SMEs strategies about sustainable development should regard the stakeholders' satisfaction as a core value, in order to generate their competitive advantages and make profit.

To increase the understanding of the relationship between the expectations of stakeholders on sustainability and company's future interests in Turkey, these can be the solutions for SMEs (Changxian et al., 2009).

1. Building up an organization culture which is built upon the needs and wants of the stakeholders

The core values, the prospects and the essence of a SME should emphasize interests and rights of every stakeholder. SMEs should be accountable for shareholders and customers, by using eco-friendly and high quality goods, treating employees equally, taking care of natural resources and environment, and also understanding the needs of local societies.

\section{Shifting the governance priority of the SMEs}

The traditional governance priority of SMEs suggests that shareholders always have to come first no matter what the cost to other stakeholders. However, this approach should be shifted to trying to understand and embrace the expectations of every stakeholder, not just the shareholders, and realizing the impact of governance decisions on them. SMEs, particularly those affecting the environment negatively, should disclose residual management and claims with each group of stakeholders.

\section{Optimum allocation of resources}

An approach for the optimum allocation of resources should be practiced so as to achieve sustainable development. Financial, human and technical resources of SMEs should give support for understanding the objectives of stakeholders. Moreover, SMEs should translate stakeholders' resources into a sort of competitive advantage, and enhance the enterprise image and reputation by optimization.

\section{Adapting organization structure}

SMEs should align their organization structure to their sustainability strategies. It is a significant feature that helps SMEs to maintain their prosperous track and be adjusted to the transformation of ecosystem towards a sustainable future. Organization structure must respect for the non-human beings in the world and the future generations needs so that our existence can continue. Moreover, SMEs can satisfy the non-social stakeholders by doing these movements. 


\section{Using green innovations}

SMEs need to concentrate their technological innovations for green products. Using these innovations give support for sustainable development, and meet the demands of stakeholders and satisfy them.

4.3 Lack of the Vision About Sustainability and Presence of Unclearly Defined Rules, Roles and Processes Within the Companies

The clearly defined rules, roles and processes help individuals, who take part in fraudulent and illegal practices (especially managers and board members), to be responsible from their actions. Moreover, they give directions for the authorization of the decisions about where and how people in various positions in the organization should be involved in decision making process. The unclear defined rules, roles and processes form a gap in a SME governance and this ambiguity provides perfect opportunities for the ones, who want to maximize their own benefits rather than the enterprise. In the meantime, the absence of the guidance for the implementation of the strategies may cause not showing willingness to take the responsibilities among the employees and the managers because of the uncertainty (CEWAS et al., 2014). The unclearness straightforwardly leads to poor management and performance. The related SME would face not satisfactory results in its operations and customer services. Besides, it will not be able to manage costs effectively. Therefore, well defined rules, roles and processes are needed to have a good governance within the SMEs.

Furthermore, the education level of the employees and the managers, and the effect of the progression of the technology are influencing the practice of sustainability. Most of the SMEs in Turkey are family owned enterprises. The education level of the personnel on those SMEs are not that high as the big companies. Since the education level is low, the vision of sustainability tends to be low accordingly. However, beside the level of education, well defined rules and regulations may help them to have at least some insight about sustainability.

In order to increase the vision on sustainability, and clearness of the rules, roles and processes in Turkey, following solutions for SMEs can be realized (CEWAS et al., 2014; Kee, 2013).

\section{Law execution.}

Firm and determined execution of law on sustainability for SMEs in Turkey is vital. It is a significant variable to increase awareness on sustainability for the ones who do not know or care about the concept. If there are more laws about sustainability issues, then there will be less harm by the people to the environment since people will be obligated to do so because of the fear of the punishment and be aware of the good behavior.

2. Unbiased and objective rules on corporate governance.

There are no guidelines for corporate governance among SMEs in Turkey to decrease the opportunistic behavior of the managers. SMEs should have good corporate governance models, which includes transparency, accountability and reliability of the employees, suppliers and consumers. It should also include motivating incentives for the board members and management to seek after goals in accordance with the enterprise's and public interest.

4.4 Lack of Skills to Analyze the Short and Long Term Effects to the Company of not Taking Sustainability Concept into Decision Making Mechanisms

SMEs use less formal instruments for the sustainability management. They prefer to have an authorized individual to react to sustainability-linked issues rather than having a formal structure of a sustainability management system. The underlying reason for this approach is, that they do not understand and appreciate the long-term effects, usefulness and effectiveness of adapting sustainability in their business models (Johnson, 2012).

First of all, it should be noted that SMEs do not make long-term plans by their structure and they do not usually employ a planning specialist. The plans are usually done by the owners, partners or top managers. Thus, it creates a big disadvantage for SMEs since their planning are based on intuitions and gut feelings rather than scientific, statistical or advanced methods and techniques of planning. Moreover, it may increase the margin of errors on decision-making process due to inadequate education, training or inability to access to accurate and timely information (Demirci, 2010). Therefore, SMEs should be very careful while constructing their planning and they should also take into the consideration of the changing business environment and make the necessary adjustments of their plans accordingly.

There is a well-known saying that goes like "money is root of all evil". It is the truth that most of the SMEs are only profit minded enterprises since they wish to get larger. Some of the SMEs do not want to adopt sustainability practice, although they are aware of the concept. They are likely to disregard business ethics as they think that it does not bring money to the enterprise immediately. The only thing they take into consideration is earning more money. 
However, they are neglecting that poor management on wastes, energy and etc. would cause them to have lower net profits in the long run. Accordingly, this would also affect their investors' choices (Kee, 2013). In fact, taking sustainability concept into the decision-making mechanisms will generate more benefits in the long run than the costs in the short run. By adapting sustainability practices a SME can have all the environmental and the profit benefit, customer loyalty and competitive advantage in the long term.

The most important type of planning for SMEs is the strategic planning since it will help them to see their future in the intense competitive market conditions. The strategic planning must be conducted by the constructive planning specialists. The importance of this strategic planning was being observed in 2008 economic crisis. Many of the SMEs (without a strategic plan) in Turkey have faced financially troublesome times and some of them have gone bankrupt (Demirci, 2010). The following problems among SMEs lead to failure for long-term development.

1. Not being able to specify long-term goals and objectives.

2. Not being able to analyze the limited factors to achieve long-term goals and objectives easily.

3. Not being able to develop alternative plans.

4. Trusting on intuitions rather that scientific methods for choosing the best alternative.

5. Disregarding the subordinates in the implementation of the plan.

In order to increase the ability to analyze long-term effects of the sustainability in Turkey, following suggestions can be the solutions for SMEs (Ar \& İskender, 2005).

\section{Analyzing and Planning}

In order to sustain the continuity in a dynamic environment, SMEs should analyze every aspect of the internal and external environmental conditions, plan ahead of the paths to be followed, apply necessary strategies, determine the deviations between the goals of the enterprise and obtained results by the control mechanisms.

\section{Setting Vision and Strategies}

SMEs should follow the conditions of the changing market environment, set the vision and strategy of the enterprise, and determine periodic plans, programs and targets in an accurate and correct way. Qualified personnel should be employed to make these determinations and there should be no flexibility on administrative staff while executing and implementing the plans and the practices.

\section{Increase Awareness on the Long-Term Planning}

The awareness on the long-term planning should be increased. It should be understood by the SMEs that customer loyalty, competitive advantage and earning more profit can only be achieved by the long-term planning rather than the short-term planning, since it only increases the present profit to save the day.

\section{Conclusion}

SMEs are quite important in terms of employment and increasing performance in Turkish economy. Even though they are real person establishments, the concepts such as social responsibility, social benefits and improved management structure will be the golden key for them to become successful and ensure their survival. SMEs in Turkey should leave the traditional understanding of focusing only to earn profit from operating activities to save the day and start to care about an inclusive sense of social benefits and rights. Therefore, the biggest obstacle standing in front of all SMEs is not to adapt sustainability practices in their business models, and the problems that they are having with the short comings of the management understandings. If SMEs can have success to solve those management issues then they can apply sustainability into their strategic plans and have more advantage on behalf of expanding their enterprises.

It is clear that Turkish SMEs are more inclined with economic welfare rather than ecological and social involvement. This paper has detected major management issues, which might be the underlying reasons for SMEs not applying sustainability practices. However, it might be expected that the development and implementation of sustainability action can quickly carry into practice, once the awareness increases to the desired level.

SMEs should have a clear approach at different levels of management to adopt sustainability practices. Moreover, they should consider the society's demand into their vision, mission and values, build up strong dialogs with all stakeholders, separate management from owners, make long-term strategic plans, develop efficient corporate governance model and management controls. 
There are several areas for further research. First, large-scaled questionnaire can be conducted to SMEs in Turkey to understand the level of their lack on sustainability concept and practices. Second, measurement of SMEs', which practice sustainability, progress to green growth can be conducted. Third, the explanatory indicators that are important and helpful to long-term strategic planning can be identified.

\section{References}

ACCA. (2010). Small business: A global agenda. Sydney, Australia: The Association of Certified Chartered $\begin{array}{lllll}\text { Accountant. } & \text { Retrieved } & 17 & \text { March } & \text { 2016, from }\end{array}$ www.accaglobal.com/content/global/small-business/pol-afb-sbaga.pdf

Aksümer, S. (2015). KOBI’lerin Ekonomideki Yeri, Yapısal Sorunları ve Çözüm Önerileri. Research and Information Report. Konya: Konya Chamber of Commerce.

Ar, A. A., \& İskender, H. (2005). Türkiye'de KOBI'ler ve KOBI'lerde Planlama, Uygulama ve Denetim. Mevzuat Dergisi, 87.

CEWAS, WIN, WASAZA (2014). Integrity Management Toolbox for Zambian Water Sector SME. Manual for Coaches. Willisau: CEWAS.

Collins, E., Lawrence, S., Roper, J., \& Haar, J. (2011). Sustainability and the Role of the Management Accountant. CIMA Research Executive Summary Series, 7, 14.

Davis, J. M. (2010). Early childhood education for sustainability: Why it matters, what it is, and how whole centre action research and systems thinking can help. Journal of Action Research Today in Early Childhood, 35-44. https://doi.org/10.1017/CBO9780511845390.003

Demirci, M. (2010). KOBİ'lerde Kurumsal Yönetim Uygulamasının Kara Etkisi; İstanbul İlinde Bir Uygulama (Unpublished master's thesis). Atılım University, Ankara.

Dhanoo, D. (2011). SME's and Sustainability in Europe. Retrieved from http://www.orbuk.org.uk/article/sme-s-and-sustainability-in-europe

Ergün, N. (2012). KOBİ’ler ve Girişimcilerin Türk Ekonomisindeki Yeri ve Önemi. Kalkınmada Anahtar Verimlilik Dergisi, 287.

European Commission (2004). Public Policy Initiatives to promote the Uptake of Environmental Management Systems in Small and Medium-Sized Enterprises. Final Report of the Best Project Expert Group. Brüssel: Europäische Kommission.

Freeman, R. E. (2010). Strategic Management: A Stakeholder Approach. New York, NY: Cambridge University Press. https://doi.org/10.1017/CBO9781139192675

Günerergin, M., Penbek, Ş., \& Zaptçıoğlu, D. (2012). Exploring the Problems and Advantages of Turkish SMEs for $\begin{array}{lllll}\text { Sustainability. Procedia-Social and } & \text { Behavioral }\end{array}$ https://doi.org/10.1016/j.sbspro.2012.09.998

Johnson, M. (2012, September). The Awareness and Application of Sustainability Management Tools in Small and Medium-Sized Enterprises. Paper submitted to the Corporate Responsibility Research Conference, France, Bordeaux.

Karataş, S. (1991). Küçük ve Orta Ölçekli İşletmeler. İstanbul: Veli Yayınları.

Kee, R. L. L. (2013). A Study on the Awareness of Environmental Sustainability among SMEs in Perlis, Malaysia (Unpublished Thesis). University Malaysia Perlis, Perlis.

Kocmanová, A., Hrebicek, J., \& Docekalova, M. (2011). Corporate governance and sustainability. Economics\&Management, 16, 543-550.

Kuhndt, M., Geibler, J. V., \& Villar, A. (2003). Challenges for SMEs in a globalized world economy. Industry and Environment, 26(4), 7-9.

MOD (2012). Türkiye Sürdürülebilir Kalkınma Raporu, Geleceği Sahiplenmek. İstanbul: T.R. Ministry of Development.

OECD (2010). SMEs and Green Growth: Promoting Sustainable Manufacturing and Eco-innovation in Small Firms. Paper submitted to the 'BOLOGNA+10' High-Level Meeting on Lessons from the Global Crisis and the Way 
Forward to Job Creation and Growth, France, Paris.

SAM (2010). Sustainability Governance: Portuguese Companies in an International Context. The Sustainability Yearbook. Lisboa: Sustainability Investing.

TOBB (2012). Türkiye'deki KOBİ Tanımı Retrieved December 10, 2015, from http://www.kobi.org.tr/index.php/tanimi/layout

TÜİK (2014). Girişim Özelliklerine Göre D1ş Ticaret İstatistikleri, 2014 (Press Release). Retrieved from http://www.tuik.gov.tr/PreHaberBultenleri.do?id= 18587

TÜİK (2015). Küçük ve Orta Büyüklükteki Girişim İstatistikleri, 2015 (Press Release). Retrieved from http://www.tuik.gov.tr/HbPrint.do?id=21864 